\title{
Hubungan Tingkat Risiko Musculoskeletal Disorders (MSDs) Mengguna- kan Rapid Entire Body Assessment (REBA) dengan Keluhan MSDs pada Residen Ilmu Bedah
}

\author{
${ }^{1}$ Ade P. Tubagus, ${ }^{2}$ Diana V. D. Doda, ${ }^{2}$ Herlina I. S. Wungouw \\ ${ }^{1}$ Program Studi Pendidikan Dokter Fakultas Kedokteran Universitas Sam Ratulangi Manado \\ ${ }^{2}$ Bagian Fisiologi Fakultas Kedokteran Universitas Sam Ratulangi Manado \\ E-mail: adepratiwitubagus@gmail.com; vanda.doda@gmail.com
}

\begin{abstract}
According to WHO, musculoskeletal disorders are categorized as the second rank of work-related disease. Various factors such as work, individual, and social factors can cause MSDs. These disorders play an important role in morbidity of workers such as healthcare workers. This study was aimed to analyze the correlation between the risk level of MSDs evaluated by using REBA and MSDs complaints among surgery residents. This was an analytical observational study with a cross-sectional design. The instruments used in this study were the Rapid Entire Body Assessment (REBA) worksheet and the Nordic Body Map (NBM) questionnaire. Data were analyzed with the Spearman correlation test. There were 42 surgery residents of Faculty of Medicine, Sam Ratulangi University, Manado participated in this study. The majority of them were males $(81 \%)$ and young adults $(88 \%)$. The prevalence of MSDs complaints were as follows: $60 \%$ of respondents had mild complaints, $33 \%$ had moderate complaints, and $7 \%$ had severe complaints. The bivariate analysis showed that the risk level of MSDs evaluated by REBA had a strong positive correlation with MSDs complaints $(P=0.000 ; \mathrm{r}=0.603)$. Conclusion: There was a significant correlation between risk level of MSDs evaluated by using REBA and the MSDs complaints. Based on the results, ergonomics interventions are recommended to surgery residents in order to prevent the occurence of MSDs.
\end{abstract}

Keywords: musculoskeletal disorders (MSDs), REBA, surgery residents

\begin{abstract}
Abstrak: Musculoskeletal disorders (MSDs) menurut WHO berada di urutan kedua terbanyak penyakit akibat kerja. Berbagai faktor seperti pekerjaan serta faktor individu dan sosial dapat menyebabkan terjadinya MSDs. Gangguan ini berperan dalam morbiditas di banyak bidang pekerjaan salah satunya di bidang kesehatan. Penelitian ini bertujuan untuk mengetahui hubungan tingkat risiko MSDs menggunakan REBA dengan keluhan MSDs pada residen ilmu bedah. Jenis penelitan ialah analitik observasional dengan desain potong lintang. Alat ukur yang digunakan ialah lembar kerja Rapid Entire Body Assessment (REBA) dan kuesioner Nordic Body Map (NBM). Analisis data menggunakan uji korelasi Spearman. Hasil penelitian mendapatkan sebanyak 42 residen ilmu bedah Fakultas Kedokteran Universitas Sam Ratulangi Manado menjadi responden penelitian. Mayoritas responden berjenis kelamin laki-laki (81\%) dan berada dalam kategori dewasa muda (88\%). Prevalensi keluhan MSDs ialah 60\% keluhan MSDs ringan, 33\% keluhan sedang, dan 7\% keluhan berat. Hasil uji korelasi Spearman mendapatkan tingkat risiko MSDs menggunakan REBA memiliki hubungan positif kuat dengan keluhan MSDs $(P=0,000, r=0,603)$. Simpulan: Terdapat hubungan bermakna antara tingkat risiko MSDs menggunakan REBA dengan keluhan MSDs. Berdasarkan hasil penelitian maka direkomendasikan intervensi ergonomi pada residen bedah untuk mencegah terjadinya keluhan MSDs.
\end{abstract}

Kata kunci: musculoskeletal disorders (MSDs), REBA, residen bedah 
Musculoskeletal disorders (MSDs) merupakan salah satu penyakit akibat kerja (PAK). Gangguan ini berperan dalam morbiditas di berbagai bidang pekerjaan dan dikenal sebagai masalah kesehatan kerja yang penting karena menyebabkan peningkatan kompensasi biaya kesehatan, mengurangi produktivitas pekerja, menurunkan kualitas hidup, memilih beralih ke pekerjaan yang lain, bahkan dapat menyebabkan disabilitas pekerja. $^{1,2}$

Berdasarkan data dari WHO Global Plan of Action on Workers' Health 20082017 tercatat bahwa MSDs berada di urutan kedua terbanyak penyakit akibat kerja setelah penyakit saluran pernapasan. ${ }^{3}$

Data statistik dari Labour Force Survey tahun 2016/2017 di Britania Raya menampilkan 1.299.000 kasus penyakit akibat kerja dan 507.000 kasus (39\%) merupakan MSDs. Di Britania Raya total kasus baru WMSDs di tahun 2016/2017 sebanyak 159.000 atau 480 kasus dari 100.000 pekerja dan terjadi kehilangan kira-kira 8.900.000 hari kerja dengan rata-rata 17,6 hari tiap kasus. ${ }^{4}$ Data dari Occupational Safety and Health Administration (OSHA) tahun 2011 menunjukkan 54\% cedera pada tenaga kerja di rumah sakit ialah MSDs.

Data dari Pusat Data dan Informasi Kementerian Kesehatan RI menunjukkan jumlah kasus PAK di Indonesia tahun 2011-2014 sebanyak 40.694 kasus. Provinsi dengan jumlah kasus PAK tertinggi tahun 2011 ialah Jawa Tengah, Sulawesi Utara, dan Jawa Timur; tahun 2012 ialah Sumatera Utara, Sumatera Selatan, dan Jawa Barat; tahun 2013 ialah Banten, Gorontalo, dan Jambi; serta tahun 2014 ialah Bali, Jawa Timur, dan Sulawesi Selatan. ${ }^{6}$

Kelompok profesi pekerjaan di bidang kesehatan diketahui berisiko tinggi untuk menderita MSDs khususnya yang memiliki profesi sebagai dokter yang melakukan tindakan prosedural seperti dokter spesialis bedah dan dokter spesialis intervensi lainnya. ${ }^{7}$ Hal ini disebabkan oleh postur yang statis dan tidak normal (awkward posture), durasi kerja yang lama, melibatkan gerakan repetitif serta model instrumen yang berbeda-beda, dimana semua hal ini tidak sesuai dengan prinsip ergonomi. Pada akhirnya kondisi tersebut akan menimbulkan MSDs. Pajanan yang terus-menerus dan ditambah stresor psikososial akan memperberat cedera muskuloskeletal. ${ }^{8,9}$

\section{METODE PENELITIAN}

Jenis penelitian ini ialah analitik observasional dengan desain potong lintang. Penelitian dilakukan di Bagian Ilmu Bedah Fakultas Kedokteran Universitas Sam Ratulangi Manado sejak bulan September sampai November 2018. Sampel penelitian ini ialah sebagian dari populasi terjangkau yang memenuhi kriteria inklusi dan eksklusi yaitu sebanyak 42 residen ilmu bedah.

Instrumen yang digunakan yaitu kuesioner Nordic Body Map (NBM) untuk mengetahui keluhan MSDs dan lembar kerja Rapid Entire Body Assessment (REBA) untuk mengetahui tingkat risiko MSDs. Data diolah dengan menggunakan program pengolah data dan dianalisis secara univariat dan bivariat menggunakan uji korelasi Spearman.

\section{HASIL PENELITIAN}

Tabel 1 memperlihatkan sebanyak 42 residen ilmu bedah diikutsertakan sebagai responden penelitian, terdiri dari 34 orang laki-laki $(81 \%)$ dan 8 orang perempuan (19\%). Responden yang mengikuti penelitian terbanyak pada kategori dewasa muda dengan rentang usia 26-35 tahun yaitu 37 orang (88\%). Pada penelitian ini sebagian besar responden berada pada kelompok durasi operasi yang lama (>2 jam/hari) yaitu sebanyak 37 orang (88\%), sedangkan untuk jumlah operasi terbanyak terdapat pada kelompok jumlah operasi 5-10 kali/ minggu yaitu 25 orang $(60 \%)$ dan yang paling sedikit pada kelompok jumlah operasi $>15 \mathrm{kali} /$ minggu yaitu 1 orang $(2 \%)$.

Tabel 2 memperlihatkan bahwa semua responden mengalami keluhan MSDs dan yang terbanyak ialah keluhan MSDs ringan pada 25 orang $(60 \%)$. Keluhan MSDs sedang didapatkan pada 14 orang (33\%) dan keluhan MSDs berat pada 3 orang (7\%). 
Tabel 3 menunjukkan bahwa keluhan MSDs dari responden paling banyak ditemukan pada regio leher (93\%) dan yang paling sedikit ditemukan pada regio bahu $(67 \%)$.

Tabel 4 memperlihatkan bahwa berdasarkan tingkat risiko MSDs (REBA), jumlah terbanyak ditemukan pada responden yang memiliki tingkat risiko MSDs sedang $(74 \%)$; tidak ditemukan responden yang memiliki tingkat risiko rendah.

Tabel 1. Distribusi menurut karakteristik responden

\begin{tabular}{lcc}
\hline $\begin{array}{c}\text { Karakteristik } \\
\text { responden }\end{array}$ & n & $\begin{array}{c}\text { Persentase } \\
(\%)\end{array}$ \\
\hline Jenis kelamin & & \\
$\quad$ Laki-laki & 34 & 81 \\
Perempuan & 8 & 19 \\
Total & 42 & 100 \\
Usia (tahun) & & \\
26-35 & 37 & 88 \\
$36-45$ & 5 & 12 \\
Total & 42 & 100 \\
Durasi operasi & & \\
(jam/hari) & & \\
$\leq 2$ & 5 & 12 \\
$>2$ & 37 & 88 \\
Total & 42 & 100 \\
Jumlah operasi & & \\
(kali/minggu) & & \\
$<5$ & 10 & 24 \\
$5-10$ & 25 & 60 \\
$11-15$ & 6 & 14 \\
$>15$ & 1 & 2 \\
Total & 42 & 100 \\
\hline
\end{tabular}

Tabel 5 menunjukkan bahwa berdasarkan uji Spearman didapatkan hubungan bermakna antara tingkat risiko MSDs menggunakan REBA dengan keluhan MSDs $(P=0,000)$. Terdapat hubungan kuat antara tingkat risiko MSDs menggunakan REBA dengan keluhan MSDs $(r=0,603)$. Hubungan tersebut berpola positif yang artinya semakin tinggi tingkat risiko MSDs maka semakin berat keluhan MSDs yang akan dirasakan (Tabel 5).

Tabel 2. Distribusi menurut keluhan MSDs

\begin{tabular}{lcc}
\hline $\begin{array}{c}\text { Keluhan } \\
\text { MSDs }\end{array}$ & n & $\begin{array}{c}\text { Persentase } \\
(\boldsymbol{\%})\end{array}$ \\
\hline Ringan & 25 & 60 \\
Sedang & 14 & 33 \\
Berat & 3 & 7 \\
Total & 42 & 100 \\
\hline
\end{tabular}

Tabel 3. Gambaran persentase keluhan MSDs berdasarkan regio tubuh

\begin{tabular}{lc}
\hline \multicolumn{1}{c}{ Regio tubuh } & $\begin{array}{c}\text { Persentase } \\
(\boldsymbol{\%})\end{array}$ \\
\hline Leher & 93 \\
Bahu & 67 \\
Anggota gerak atas & 71 \\
Anggota gerak bawah & 83 \\
Punggung atas & 74 \\
Punggung bawah & 86 \\
\hline
\end{tabular}

Tabel 4. Distribusi menurut tingkat risiko MSDs menggunakan REBA

\begin{tabular}{lcc}
\hline $\begin{array}{c}\text { Tingkat risiko } \\
\text { MSDs (REBA) }\end{array}$ & n & $\begin{array}{c}\text { Persentase } \\
(\%)\end{array}$ \\
\hline Rendah & 0 & 0 \\
Sedang & 31 & 74 \\
Tinggi & 11 & 26 \\
Total & 42 & 100 \\
\hline
\end{tabular}

Tabel 5. Analisis bivariat tingkat risiko MSDs (REBA) dengan keluhan MSDs

\begin{tabular}{cccc}
\hline \multicolumn{1}{c}{ Variabel } & n & r & P value \\
\hline $\begin{array}{l}\text { Tingkat risiko MSDs (REBA) } \\
\text { dengan keluhan MSDs }\end{array}$ & 42 & 0,603 & 0,000 \\
\hline
\end{tabular}

\section{BAHASAN}

Hasil penelitian ini memperlihatkan bahwa semua responden mengalami keluhan MSDs dan yang terbanyak ialah keluhan
MSDs ringan (60\%). Regio tubuh yang paling sering dikeluhkan responden ialah regio leher yaitu sebanyak $93 \%$. Morbiditas servikal pada dokter bedah merupakan hal 
yang lazim. Penelitian yang dilakukan oleh Tirgar et al. ${ }^{10}$ pada 45 responden dokter bedah mendapatkan leher $(66,7 \%)$ dan punggung bawah $(51 \%)$ merupakan regio yang paling sering mengalami keluhan MSDs. Keluhan regio leher pada dokter bedah biasanya diakibatkan karena posisi leher yang tidak ergonomis selama pembedahan.

Hasil observasi peneliti berdasarkan dokumentasi pada saat penelitian menunjukkan bahwa didapatkan postur tubuh yang tidak normal (awkward) pada residen ilmu bedah saat melakukan pembedahan. Berdasarkan REBA, semakin tidak normal postur tubuh maka akan semakin tinggi tingkat risiko MSDs yang akan terjadi. Penelitian ini menunjukkan bahwa responden paling banyak memiliki tingkat risiko sedang untuk terjadinya MSDs (74\%). Penelitian yang dilakukan oleh Vaidya et al. ${ }^{7}$ pada 50 dokter bedah di Nepal menunjukkan bahwa terdapat 41 responden bekerja dalam postur statis dalam waktu yang lama dan 43 responden harus sedikit membungkukkan badan saat melakukan pekerjaan. Hal ini menunjukkan bahwa memang benar postur tubuh dokter bedah saat melakukan operasi tidak sesuai dengan prinsip ergonomi.

Hasil penelitian ini menunjukkan adanya hubungan bermakna antara tingkat risiko MSDs yang diukur menggunakan REBA dengan keluhan MSDs yang dialami oleh residen ilmu bedah. Hal ini didukung oleh beberapa penelitian sebelumnya yang dilakukan terhadap dokter bedah baik dokter ahli maupun residen dimana postur tubuh menjadi faktor ergonomi paling penting yang berhubungan dengan keluhan MSDs. ${ }^{11-13}$ Penelitian ini tidak selaras dengan hasil penelitian yang dilakukan oleh Taylor et al. ${ }^{14}$ yang melaporkan bahwa tidak terdapat hubungan antara postur tubuh saat melakukan pembedahan dan keluhan MSDs pada dokter bedah mulut dan maksilofasial. Hal ini mungkin disebabkan karena Taylor et al. melakukan penilaian postur tubuh saat operasi dan keluhan MSDs menggunakan metode yang berbeda dengan REBA dan Nordic.
Dokter bedah memiliki risiko yang lebih tinggi untuk mengalami keluhan MSDs dikarenakan selain postur tubuh yang statis dan awkward ditemukan juga hubungan antara keluhan MSDs dengan faktor seperti tetap melanjutkan pembedahan meskipun dalam keadaan lelah dan kurangnya istirahat. Beberapa faktor lain yang memperberat keluhan MSDs dari dokter bedah ialah stres mental karena memiliki rasa tanggung jawab yang tinggi terhadap kesehatan pasien. ${ }^{10,15,16}$

Pada penelitian oleh Voss et al. ${ }^{17}$ didapatkan bahwa sebagian besar dokter bedah $(91 \%)$ berpendapat bahwa pelatihan tentang ergonomi saat residensi sangat diperlukan namun hanya 52\% dokter bedah yang memiliki kesadaran dan pengetahuan tentang ergonomi pada saat pembedahan. Oleh karena alasan diatas maka diperlukan kesadaran dokter ahli dan residen bedah tentang pentingnya ergonomi dalam kamar operasi.

Penelitian ini menunjukkan tingkat risiko sedang untuk terjadinya MSDs dimana berdasarkan REBA diperlukan intervensi ergonomi. Intervensi ergonomi dalam hal ini berupa postur tubuh yang baik meliputi posisi kepala yang netral dan tegak, elevasi bahu yang tidak lebih dari 90 derajat, lengan atas yang adduksi, lengan bawah yang tidak menggantung, sudut fleksi siku yang tidak melebihi 90-120 derajat, minimal deviasi dari ulnar atau radial, minimal fleksi dari pergelangan tangan, serta perlu dihindari torsi tulang belakang dan postur yang membungkuk. Penyimpangan dari postur netral akan menyebabkan keluhan MSDs.

Selain postur tubuh yang baik, melakukan istirahat sebentar sementara operasi untuk mengurangi keluhan pada regio tubuh yang terlibat juga direkomendasikan. Intervensi ergonomi seperti meletakkan instrumen yang paling sering dipakai dekat dengan tubuh operator dan yang lebih jarang digunakan dapat lebih jauh dari tubuh operator untuk menghindari torsi dari tulang belakang atau batang tubuh. Perlu diperhatikan penyesuaian ergonomi di kamar operasi untuk mencegah terjadinya 
keluhan MSDs pada dokter ahli dan residen bedah. $^{18}$

\section{SIMPULAN}

Berdasarkan hasil penelitian ini dapat disimpulkan bahwa terdapat hubungan bermakna antara tingkat risiko musculoskeletal disorders menggunakan REBA dengan keluhan musculoskeletal disorders pada residen ilmu bedah.

\section{SARAN}

Disarankan untuk melakukan intervensi ergonomi untuk mengurangi keluhan MSDs pada dokter bedah baik dokter ahli maupun residen. Intervensi ergonomi dapat berupa perubahan postur tubuh saat pembedahan, penggunaan alat penyokong tubuh, penggunaan meja operasi yang dapat diatur sesuai dengan tinggi badan operator, penggunaan tempat duduk, dan kamar operasi dengan pencahayaan yang cukup.

Disarankan untuk penelitian lanjut dengan menggunakan faktor risiko yang lain sebagai variabel seperti durasi operasi, jumlah operasi, IMT dan faktor psikososial. Penelitian demikian juga dapat dilakukan terhadap responden residen atau dokter ahli yang juga melakukan pembedahan seperti obstetri-ginekologi, THT-KL, dan mata

\section{DAFTAR PUSTAKA}

1. World Health Organization. Occupational health: a manual for primary health care workers. Cairo. Epub ahead of print, 2001.

2. Djauzi S, Karjadi T. Dasar-dasar penyakit akibat kerja. In: Buku Ajar Ilmu Penyakit Dalam Jilid III (6th ed). Jakarta: Interna Publishing, 2015; p. 3944-6.

3. World Health Organization. WHO global plan of action on workers' health (20082017): Baseline for implementation. 2013; p. 1-46.

4. Health and Safety Executive. Work-related musculoskeletal disorders (WRMSDs) statistics in Great Britain 2017. Work Musculoskelet Disord Stat Gt Britain 2017;1(1):22.

5. OSHA. Caring for our caregivers: Facts about hospital worker safety. 2013; p. 1-32.
6. Pusat Data dan Informasi Kementerian Kesehatan RI. Infodatin: Situasi kesehatan kerja, 2015.

7. Vaidya A, Sainju N, Joshi S. Work related musculoskeletal disorders among surgeons working in a tertiary care hospital in Kathmandu, Nepal. Int J Occup Saf Heal. 2015;5(2):6-10.

8. Epstein S, Sparer EH, Tran BN, Ruan QZ, Dennerlein JT, Singhal D, et al. Prevalence of work-related musculoskeletal disorders among surgeons and interventionalists: A systematic review and meta-analysis. JAMA Surg. 2018;153(2): e174947. doi: 10.1001/ jamasurg.2017.4947.

9. Jain NB, Higgins LD, Losina E, Collins J, Blazar PE, Katz JN. Epidemiology of musculoskeletal upper extremity ambulatory surgery in the United States. BioMed Cent Musculoskelet Disord. 2014;15(4):1-7. doi: 10.1186/14712474-15-4

10. Tirgar A, Khallaghi S, Taghipour M. A study on musculoskeletal disorders and personal and occupational risk factors among surgeons. IJHS. 2013;1(1):50-7.

11. Godwin Y, Macdonald C, Kaur S, Zhelin L, Baber C. The impact of cervical musculoskeletal disorders on UK consultant plastic surgeons: can we reduce morbidity with applied ergonomics? Ann Plast Surg. 2017;78(6): 602-10.

12. Aghilinejad M, Ehsani AA, Talebi A, Koohpayehzadeh J, Dehghan N. Ergonomic risk factors and musculoskeletal symptoms in surgeons with three types of surgery: open, laparoscopic, and microsurgery. Med J Islam Repub Iran. 2016;30(1):467.

13. Knudsen ML, Ludewig PM, Braman JP. Musculoskeletal pain in resident orthopaedic surgeons: results of a novel survey. Iowa Orthop J. 2014;34:190-6.

14. Taylor CA, Strauss RA, Best AM. Postural Preference and musculoskeletal complaints in oral and maxillofacial surgeons. J Oral Maxillofac Surg. 2018; 76(1):46-51.

15. Memon AG, Naeem Z, Zaman A, Zahid F. Occupational health related concerns among surgeons. Int J Heal Sci. 2016; 10(2):279-91.

16. Doda DVD. Prevention of musculoskeletal 
pain and discomfort in South Australian workplaces: evaluation of a stage of change approach. Adelaide, South Australia. Available from: https:// digital.library.adelaide.edu.au/dspace/h andle/2440/85187 (2014)

17. Voss RK, Chiang YJ, Cromwell KD, Urbauer DL, Lee JE, Cormier JN, et al. Do no harm, except to ourselves? A survey of symptoms and injuries in oncologic surgeons and pilot study of an intraoperative ergonomic intervention. J Am Coll Surg. 2017;224(1):1625.e1..

18. Ganer N. Work related musculoskeletal disorders among healthcare professional and their preventive measure: a report. Ijsrset. 2016;2(4):693-8. 